\title{
Clinical Competence for Systemic Lupus Erythematosus in Primary Care
}

Carlos E. Cabrera-Pivaral ${ }^{1,2 *}$, Guillermo J Gonzalez Perez ${ }^{1}$, Jorge Iván Gámez-Nava ${ }^{2,3}$, Maria G. Vega López ${ }^{1}$, Arnulfo Nava ${ }^{2,3}$ and Mario Salazar Paramo ${ }^{1,2}$

${ }^{1}$ Postgraduate Program of Public Health Sciences, Universidad de Guadalajara, Mexico

${ }^{2}$ Director of Continuing Health Education and Research, Instituto Mexicano del Seguro Social, Mexico

${ }^{3}$ Division of Musculoskeletal and Autoimmune Diseases, Clinical Epidemiology Research Unit, Mexico

\begin{abstract}
Objective: To evaluate the competence of the primary care physicians for the evaluation of Systemic lupus erythematosus.

Patients and Methods: In a cross-sectional survey we included primary care physicians working at the official Mexican Social Security Institute that provides nation-wide health-care for salaried workers. Four hospitals from 23 potentially eligible primary-care hospitals in Guadalajara, Mexico were randomly selected. From these hospitals the physicians that agree to participate were asked to answer a questionnaire for clinical competence. Using a Delphi modified approach; this questionnaire was elaborated by a group of rheumatologists and researchers working in continuing medical education. A Kuder-Richardson reliability index was computed in 0.94 . The diseases included in the questionnaire were Systemic lupus erythematosus and questions regarding to these were made using the technique of "representative patients". Domains included in the questionnaire were: assessment of risk factors, strategies for diagnosis, and treatment. According to the scores obtained in the questionnaire the ranges for clinical competence were: very high level, high level, moderate, low, very low and points was considered as obtained by chance.
\end{abstract}

Results: One-hundred and four primary care physicians were interviewed. From the total $60(58 \%)$ physicians had the speciality of family physician. Only $11 \%$, of the interviewed had a high level of competence according to the instrument. Moderate competence was achieved by $20 \%$, whereas suboptimal levels had $51 \%$ : being low $31 \%$, very low $20 \%$. An additional $18 \%$ had scores obtained by chance. There was no statistical difference in the scores between physicians with or without the specialty in family medicine.

Conclusions: These results pointed-out a sub-optimal competence in a significant proportion of the primary care-physicians attending Systemic lupus erythematosus. Higher efforts need to be made to increase the levels of competence and improve the effectiveness of continual medical education for these physicians.

Keywords: Primary care physicians; Clinical competence; Autoimmunity; Systemic lupus erythematosus; Educational research

\section{Introduction}

It is estimated that rheumatic disorders have a high prevalence in Mexico [1]. These disorders constitute an important cause for disability, work limitations and increase in the health requirements for the Society [2-3].

In primary-care hospitals, musculoskeletal symptoms or specific diseases constitute between 9 to $20 \%$ of the visits to physicians [4-6] Most of these patients have never been seen by rheumatologists and it is difficult that the system support the reference of all of these patients [7]. Therefore, primary care physicians (PCP) are the ancillary stone in order to provide this care, and in consequence, questions on their clinical competence regarding rheumatic disorders arise.

This clinical competence in physicians can be defined as the skills to evaluate and solve clinical problems, using the reasoning and clinical judgement as relevant tools [8]. The adequate diagnosis, therapeutics and medical counceil are an important aspect of the clinical competence. In Mexico, there is a lack of studies evaluating the competence of the primary-care physicians (PCP) for the evaluation, diagnosis and treatment of the Systemic lupus erythematosus. Therefore, in the present study we evaluated the clinical competence of the PCP for the diagnosis, to referrer to rheumatologist and to treat properly common Systemic lupus erythematosus.

\section{Patients and Methods}

Cross-sectional survey

\section{Clinical setting}

Four-hundred and fifty PCP working in primary-care hospitals from the Mexican Institute of Social Security (IMSS) at Guadalajara city in Mexico were interviewed. The inclusion criteria were: be working fulltime as PCP in the IMSS, in the out-patient clinic of primary-care and agree to participate voluntarily. The exclusion criteria were: physicians working at emergency rooms or in other departments that no evaluate out-patients.

Four clinics out of 23 primary-care hospitals attending patients at the city were selected using a simple sampling through number generated by a computer. From the 4 clinics the total of PCP potentially eligible was 104 , and all of them were interviewed.

\section{Assessment of clinical competence}

Using a Delphi modified approach a questionnaire was designed by

*Corresponding author: Carlos E. Cabrera-Pivaral, Professor, Postgraduate Program of Public Health Sciences, Universidad de Guadalajara, San Juan Bosco 3782 1000, Guadalajara, Jalisco, México, Tel/ Fax: 01-3-33-1210345; E-mail: carlos.cabrera@imss.gob.mx

Received April 14, 2012; Accepted April 20, 2012; Published April 14, 2012

Citation: Cabrera-Pivaral CE, Perez GJG, Gámez-Nava JI, López MGV, Nava A et al. (2012) Clinical Competence for Systemic Lupus Erythematosus in Primary Care. J Aller Ther 3:e106. doi:10.4172/2155-6121.1000e106

Copyright: (c) 2012 Cabrera-Pivaral CE, et al. This is an open-access article distributed under the terms of the Creative Commons Attribution License, which permits unrestricted use, distribution, and reproduction in any medium, provided the original author and source are credited. 
a consensus of experts in rheumatic diseases composed by researchers with experience in questionnaire designs, 2 family physicians and 2 rheumatologists who elaborated the questions considered relevant for 3 domains of the clinical competence based in representative cases of patients with Systemic lupus erythematosus. These diseases were selected because of their prevalence or their transcendence in morbidity or mortality. The domains included in the assessment were risk factors, diagnosis, and treatments. They selected a panel of relevant questions for the pilot survey. The questions were close-ended with 3 options for the answers: true, false or I do not know. In a final round of the Delphi modified procedure, those questions considered as not relevant by the experts were eliminated; the final questionnaire was conformed by 35 questions and 3 domains of the clinical competence constituted by comprehension of risk factors, methods for diagnosis, and treatment. The reliability index of the instrument computed by Kuder - Richardson was 0.94. The responses were computed in the next basis: each correct answer was equivalent to 1 point in the score, each wrong answer was equivalent to -1 point and an answer of "I do not know" accounted by 0 points. The total score of the questionnaire was computed as the difference from correct answers and to substract from this result the incorrect answers. It is important from the educational research point of view to draw attention that the total score obtained from this questionnaire may reach negative values. According to the points obtained in the final score was classified on the following levels that of clinical competence: very high level 30-35 points, high level 25-29, moderate 20-24, low 15-19, very low $10-14$ and $<9$ points was considered as obtained by chance [9]. In the present study, assumption was made that clinical competence may identify performance of the family physician to identify a Systemic lupus erythematosus, perform an appropriate diagnosis, and to establish adequate treatment and proper reference to rheumatologist. Other variables assessed were: gender, age, presence of specialty in family medicine, years of practicing medicine, to be contracted in a job temporary or permanent.

\section{Results}

One hundred and four primary care physicians participated in this study; their general characteristics are described in Table 1 and include among others that fifty-six PCP (53\%) were male, 58\% had the specialty in family medicine and $84 \%$ had a permanent contract for working in the hospital.

Table 2 shows the different levels of clinical competence achieved by the PCP. Only $11 \%$ (95\%CI 5-17), of the interviewed had a high level

\begin{tabular}{|c|l|l|}
\hline Working Status & Frequency & Percent \\
\hline Permanent Contract & 87 & 84 \\
\hline Temporary Contract & 17 & 16 \\
\hline Gender & & \\
\hline Male & 56 & 53.5 \\
\hline Female & 48 & 46.5 \\
\hline Family Medicine Specialty & & \\
\hline Yes & 60 & 58 \\
\hline No & 44 & 42 \\
\hline Age (years) & & \\
\hline $28-40$ & 39 & 37 \\
\hline $41-54$ & 58 & 57 \\
\hline $55-67$ & 7 & 6 \\
\hline Duration of Family Medicine Practice (years) & & \\
\hline $1-9$ & 27 & 26 \\
\hline $10-19$ & 51 & 48 \\
\hline $20-28$ & 26 & 26 \\
\hline
\end{tabular}

Table 1: General Features of 104 Primary Care Physicians.

\begin{tabular}{|ll|l|l|l|}
\hline \multicolumn{2}{|l|}{ Clinical Competence Levels (Points) } & Frequency & Percent \\
\hline $\mathbf{1}$ & Random & $(<9)$ & 19 & 18.26 \\
\hline $\mathbf{2}$ & Very Low & $(10-14)$ & 21 & 20.19 \\
\hline $\mathbf{3}$ & Low & $(15-19)$ & 32 & 30.76 \\
\hline $\mathbf{4}$ & Medium & $(20-24)$ & 21 & 20.19 \\
\hline $\mathbf{5}$ & High & $(25-29)$ & 11 & 10.57 \\
\hline $\mathbf{6}$ & Very High & $(>30)$ & 0 & 0 \\
\hline
\end{tabular}

Table 2: Clinical Competence for Systemic lupus erythematosus in 104 Primary Care Physicians.

of competence according to the instrument. Moderate competence was achieved by $20 \%$ (95\%CI 13-27), whereas suboptimal levels had 51\%: being low $31 \%$ (95\%CI 22-40), very low 20\% (95\%CI 13-27). An additional $18 \%$ had scores obtained by chance (95\%CI 11-25). Overall the median of scores obtained by the interviewees was 13.3 (ranges -4 to 31). There was no statistical difference in the scores between physicians with or without the specialty in family medicine $(\mathrm{p}=0.36)$. Neither the type of contratation was related with the clinical competence $(\mathrm{p}=0.25)$ or the years of be working as PCP ( $\mathrm{p}=0.36)$.

\section{Discussion}

The results of the present survey showed a suboptimal level of clinical competence of the PCP to evaluate and treat rheumatic disorders. These deficiencies were similar in PCP who had the specialty in family medicine as well as those who had not.

This finding underlines the importance of the evaluation of the results of the competence of the clinicians for the diagnosis of diseases. The clinical competence in primary care Units seems to be suboptimal and better efforts need to be made to improve it. An interesting finding was that the presence of specialty in family medicine was not associated with increase in the scores for competence in the questionnaire.

An interesting survey made by mail to primary care physicians in Chile about their self-perceived strengths, weakness, and self-confidence for the management of rheumatic diseases, shows that PCP scored low both the difficulties to refer a rheumatologist and for access to continuous medical education [10]. The confidence for the management, diagnosis and knowledge was lower for Systemic lupus erythematosus [10]. Several studies regarding to PCP competence for chronic disorders such as diabetes mellitus and systemic arterial hypertension observed similar results to our own survey with low scores for competence that were no increased in those with specialty in family medicine [11-12].

Our results are indicative of the need to re-evaluate the structure of programs for continuous medical education in rheumatology as an important aspect of the curricula for the family physician. Rheumatic disorders constitute an important problem of Health in Mexico and are important to highlight several reasons to be taken into account these disorders in family medicine. These reasons include that there is a high frequency of medical consults related with rheumatic disorders in both primary and secondary-care hospitals [6-7]. In México the rheumatic diseases constituted the fourth cause for work disability in salaried workers in the $2000[13,14]$. A key strategy to decrease the impact of these disorders in the rates of work disability is to establish an appropriate diagnosis and treatment early on the onset of the disease, therefore, it is critically important that the PCP has the clinical competence to evaluate, refer and treat these disorders. However, it is not possible that the PCP can refer all the patients with these disorders to a rheumatologist in most of the health systems. Some studies have published an important delay between the onset of the disease and the referral to the rheumatologist $[15,16]$. Therefore, many of the initial diagnostic strategies as well as the 
Citation: Cabrera-Pivaral CE, Perez GJG, Gámez-Nava JI, López MGV, Nava A, et al. (2012) Clinical Competence for Systemic Lupus Erythematosus in Primary Care. J Aller Ther 3:e106. doi:10.4172/2155-6121.1000e106

Page 3 of 3

early treatment is instituted by the PCP and these strategies can influence significantly in the functional prognosis, morbi-mortality and the subsequent response of the patients $[17,18]$.

A greater inculcation between rheumatologists and PCP it is required to increase the effectiveness of the courses in continual medical education to these physicians [19-22]. Other important challenge is to transform the traditional model of classical education into a participative model. Because this model is more oriented to the reflection as a tool for recuperation of experiences about aspects related to the diagnosis and treatment. Promoting the participation of the subject in training in the generation of knowledge using the active and oriented seeking [20], moreover knowing that perception of PCP regarding success rate of interventions influence its decision making [21].

\section{References}

1. Cardiel MH, Rojas-Serrano J (2002) Community based study to estimate prevalence, burden of illness and help seeking behaviour in rheumatic diseases in Mexico City. A COPCORD study. Clin Exp Rheumatol 20: 617-624.

2. Zamora L, Arellano M, Kuntsmann S, Montenegro A, Riveros B, et al. (1997) Disability in the private pension system in Chile. Rev Méd Chile 125: 99-106.

3. Badley E, Rasooly I, Webster GK (1994) Relative importance of musculoskeleta disorders as a cause of chronic health problems, disability and health care utilization: findings from the 1990 Ontario Health Survey J Rheumatol 21: 505514

4. Rosemblatt R, Cherkin D, Schneeweiss R, Hart LG, Greenwald H, et al. (1982) The structure and content of family practice: Current status and future trends. J Fam Pract 15: 681-722.

5. Felts W, Yelin E (1989) The economic impact of the rheumatic diseases in the United States. J Rheumatol 16: 867-884

6. Pacheco D, Vizcarra G, Castillo V, Fuentealba C, Alvarez M, et al. (1997) Perfi de la consulta reumatológica. Comparación entre un policlínico de atención primaria vs uno de reumatología. Revista Chilena de Reumatología 13: 101.

7. Bjelle A (1996) Primary care and rheumatology in musculoskeletal disorders: Bridging the gap. J Rheumatol 23: 205-207.

8. Pantoja PM, Barrera MJ, Insfrán SM (2003) Instrumento para evaluar la aptitud clínica en anestesiología. Rev Med IMSS 41: 15-22.
9. Pérez-Padilla JR, Viniegra VL (1989) Method for calculating the distribution of randomly expected scores in a false-true-do not know-type of test. Rev Invest Clínica 41: 375-379.

10. Daniel Pacheco R, Héctor Gatica R, Sonia Kaliski K (2006) Self assessment of strengths, weaknesses and self confidence of primary care physicians taking care of rheumatic diseases. Rev Méd Chil 134: 813-820.

11. García Hernández A, Viniegra Velázquez L (1999) Clinical competence of the family doctor in systemic arterial hypertension. Rev Invest Clin 51: 93-98.

12. Gómez-López Víctor Manuel, García-Ruiz Martha Elena, Barrientos- Guerrero Carlos (2006) Diabetes Mellitus: Clinical aptitude of the doctor of primary care. Educ méd 9: 35-39.

13. Instituto Mexicano del Seguro Social, (2000) Boletín estadístico y epidemiológico. México D. F.

14. Secretaría de salud (2000) Boletín M estadístico, México D. F.

15. Hanly J, McGregor A, Black C, Bresnihan B (1984) Late referral of patients with rheumatoid arthritis to rheumatologists. Ir J Med Sci 153: 316-318.

16. Kidd BL, Cawley MI (1988) Delay in diagnosis of spondarthritis. Br J Rheumato 27: $230-232$.

17. Arthritis and Musculoskeletal Alliance standards of care for people with inflammatory arthritis.

18. Scottish Intercollegiate Guidelines Network. Management of early rheumatoid arthritis.

19. Lewtas J (1996) OMERED outcome measures in rheumatology education. J Rheumatol 23: 208-210.

20. Viniegra L (1988) Research as a learning tool. Rev Invest Clin 40: 191-197.

21. Ang DC, Thomas K, Kroenke K (2007) An exploratory study of primary care physician decision making regarding total joint arthroplasty. J Gen Intern Med 22: $74-79$.

22. Davies H, Archer J, Bateman A, Dewar S, Crossley J, et al. (2008) Specialtyspecific multi-source feedback: assuring validity, informing training. Med Educ 42: $1014-1020$. 